\title{
Changes in serum creatine kinase and other biological measurements associated with musculature in children recovering from kwashiorkor
}

\author{
By S. REINDORP AND R. G. WHITEHEAD \\ MRC Child Nutrition Unit, Mulago Hospital, Kampala, Uganda* \\ (Received I 5 Fune 1970-Accepted I6 September 1970)
}

I. Changes in serum creatine kinase activity, creatinine excretion, mid-upper arm and thigh muscle circumference and the ' $\mathrm{X}$-ray muscle shadow weight' of the upper arm and thigh muscles have been compared in children recovering from kwashiorkor.

2. Creatine kinase activity rose as the health of the child improved but was subject to large fluctuations mainly associated with the occurrence of infections. For this reason it is unlikely to be of value in assessing nutritional status on the basis of changes in musculature.

3. Creatinine excretion also increased with treatment and was more consistent. This measurement should be of much greater value than serum creatine kinase.

4. The anthropometric measurements were relatively insensitive to quite large changes in limb musculature.

5. Assessment of musculature by soft-tissue X-rays of the limbs appeared to be a sensitive method of potential value.

Waterlow (1956) and Mendes \& Waterlow (1958) have suggested that, as malnutrition progresses, the brunt of protein loss falls on the muscle.

Various simple methods of assessing the musculature of children of differing nutritional status have been proposed. A frequently used value is the mid-upper arm muscle circumference, obtained by calculation from the arm circumference and the skinfold thickness at the mid-point of the upper arm (Jelliffe, r966). Other workers (Garn, 1962; McFie \& Welbourn, 1962) have suggested the use of soft-tissue X-rays as an alternative to anthropometry. A biochemical estimation of body muscle mass, the $24 \mathrm{~h}$ urinary creatinine excretion, was used by Arroyave, Sandstead \& Schumacher (1958) to compare the nutritional status of rural and urban child communities of different socio-economic classes. Creatinine excretion has been used as the basis of the creatinine-height index (Viteri, Arroyave \& Béhar, I966) which is the creatinine excreted in a $24 \mathrm{~h}$ urinary sample expressed as a percentage of the creatinine which would be expected in a well-fed child of the same height.

More recently, Whitehead (1968) observed that serum creatine kinase activity was low in children with kwashiorkor. This enzyme is found predominantly in skeletal and cardiac muscle, and Balmer \& Rutishauser (1968) suggested from independent observations that the measurement might be of value in assessing musculature changes in malnourished children. It would have the advantage over creatinine measurements in that no timed urine collections would be needed.

The original reason for starting this investigation was to study the potential value of the serum creatine kinase measurement as a component in a 'biochemical profile' for

* Requests for reprints to R. G. Whitehead, PO Box 6717, Kampala, Uganda. 
assessing nutritional status, but the opportunity was taken to investigate the relative merits of the other methods which have been proposed for detecting changes in musculature.

\section{METHODS}

\section{Clinical material}

The eight severely malnourished, oedematous children described in this study were between 18 and 25 months old when they were admitted to the metabolic ward, and they were all diagnosed as cases of kwashiorkor or marasmic kwashiorkor. The type of treatment the children received as in-patients has been described by Staff (r968). They were treated in the ward for 3-5 weeks and were discharged clinically well. After discharge their progress was followed closely for a period of up to 8 months, during which time an effort was made to encourage the continuation of the child's nutritional recovery. Regular home visits were made during the first 3 months, and the mother was given powdered-milk supplements for the child and nutritional advice. The child received a clinical examination while attending the unit as an out-patient every $2-4$ weeks and any treatment necessary was given. If the child became seriously ill during this period he was readmitted to the ward until he recovered.

\section{Biochemistry}

Blood samples for creatine kinase measurement were obtained by venepuncture of the internal jugular vein; samples were taken on admission, weekly during in-patient treatment and on all subsequent visits to the ward. The serum was separated and kept at $0-4^{\circ}$ until analysed.

A $48 \mathrm{~h}$ urine collection was made from each child on admission in disposable polyethylene bags. The urine passed during each $\mathrm{i} 2 \mathrm{~h}$ period was collected separately in bottles containing $\mathrm{I} \mathrm{ml}$ concentrated hydrochloric acid and the four urine samples were stored at $20^{\circ}$ after the acidity had been adjusted to $\mathrm{pH}$ I with concentrated hydrochloric acid. Urine samples $(2 \times 12 \mathrm{~h})$ were subsequently collected before discharge and at $\mathrm{I}-2$ month intervals during the follow-up period, the child being admitted to the metabolic ward for this purpose.

Serum creatine kinase activity was assayed by the method of Hughes (I962) with the following modifications for measuring the low activities found in severe malnutrition: the volume of serum used was doubled $(0.2 \mathrm{ml})$, the enzyme reaction time was increased from 30 to $45 \mathrm{~min}$ and $\mathrm{I} \cdot 5 \mathrm{ml}$ portions of protein-free supernatant fraction were used for the colour reaction with no subsequent water dilution. The final solutions were centrifuged before the colours were measured at $520 \mathrm{~nm}$. The method was successfully carried out on occasion on smaller serum samples by reducing the volumes of all solutions to one-half or one-quarter throughout. Enzyme activity was expressed as $\mathrm{n}$-moles creatine formed/min per $\mathrm{ml}$ serum.

Urinary creatinine was estimated by the Jaffe reaction according to the method of Taussky (1956). The $\mathrm{pH}$ of the urine was adjusted to $5.5 \pm 0.5$ with concentrated sodium hydroxide, the urine was diluted with water as necessary and interfering substances were removed by ether extraction. After the addition of alkaline picrate the colours of the final solutions were read at $510 \mathrm{~nm}$. 


\section{Anthropometry}

Initially, the measurements of arm circumference and skinfold thickness were made weekly, after the loss of oedema, and then every time the child was seen after discharge. The anthropometric measurements were taken at a standard point in the left arm and right thigh as described by Standard, Wills \& Waterlow (1959). Since the humerus grows from the distal point but the femur from the proximal end, the measurements were made from the acromion process and the medial epicondyle respectively. The 'mid-upper arm' was established for the first measurement only; subsequent estimations were made at the same distance from the reference point.

A steel tape was used to measure the limb circumference and Harpenden skinfold calipers were used for the skinfold thickness measurements. In the arm, skinfold thickness was measured over the biceps and triceps muscles and the average value was used; in the thigh, only the skinfold thickness on the anterior aspect was measured because of the difficulty of obtaining accurate readings at the lateral and medial aspects in a protesting child. The lowest constant skinfold reading was recorded in all instances. The muscle circumferences of the upper arm and thigh were calculated according to Jelliffe $(\mathrm{I} 966)$ with no correction made for bone: muscle circumference $=$ limb circumference $-(\pi \times$ skinfold thickness $)$.

\section{Soft-tissue X-rays}

Concurrently with this investigation a study was made of the relative values of different muscle measurements which can be obtained from soft-tissue radiographs in malnourished children. The results will be published elsewhere (G. Jones, in preparation). The method of quantification described here is the one which the present authors considered showed the greatest accuracy.

For ethical reasons, $\mathrm{X}$-ray assessments were not made as often as the anthropometric measurements. The first $\mathrm{X}$-ray was taken during the in-patient period, after the loss of oedema, usually around 3 weeks after admission. Subsequently four more X-rays were taken at intervals during the following 6-9 months. The X-rays were of the left upper arm and right thigh with the patient placed supine on the examination table. The arm was held abducted with the elbow extended and the palm of the hand facing upwards, the tube was aligned with the centre of the film, and without undue pressure the arm was held parallel to and in contact with the cassette. For the thigh X-ray, the leg was slightly abducted and held with the knee extended and the foot pointing upwards. The pelvis was kept parallel to the table top, the thigh was kept in contact with the cassette, the mid-point of the thigh was placed in the centre of the film and the tube was again centred. A $25^{\circ} 4 \mathrm{~cm} \times 20.3 \mathrm{~cm}$ film was usually sufficient to include both the elbow and shoulder joint and a $25^{\circ} 4 \mathrm{~cm} \times 30^{\circ} 5 \mathrm{~cm}$ film for both the knee and hip joint. All X-rays were taken at an anode distance of $9 \mathrm{I}^{\circ} 4 \mathrm{~cm}$ using a I mm, fine focus tube. Standard Gevaert Curvix film was used with fast screens (Phillips Metalix for the arm and Phillips Metalix Ultra for the thigh) to reduce the exposure factors, which were adjusted to give adequate representation of both the soft tissues and bone. Low exposure was used (kilovolts peak 46 ; milliampere seconds 4 for the arm, milliampere 
seconds 6 for the thigh) with lead sheet gonad protection and a light diaphragm to reduce the field of exposure to the size of the cassette.

The weights of the muscle shadow were measured in a standard area on the X-ray as illustrated in Fig. I. The mid-point of the bones was found by drawing a line (AB) from the highest point of the metaphysis of the humerus or femur down the bone through the centre of a line drawn between the two well-defined epicondyles (CD). The length of this line from the highest to the lowest point of the metaphysis was measured and half the distance was taken as the mid-point of the bone. Another line was drawn (EF), from this point, parallel to CD to both edges of the muscle shadow. The muscle shadow on the X-ray was cut out on both sides of the bones between the
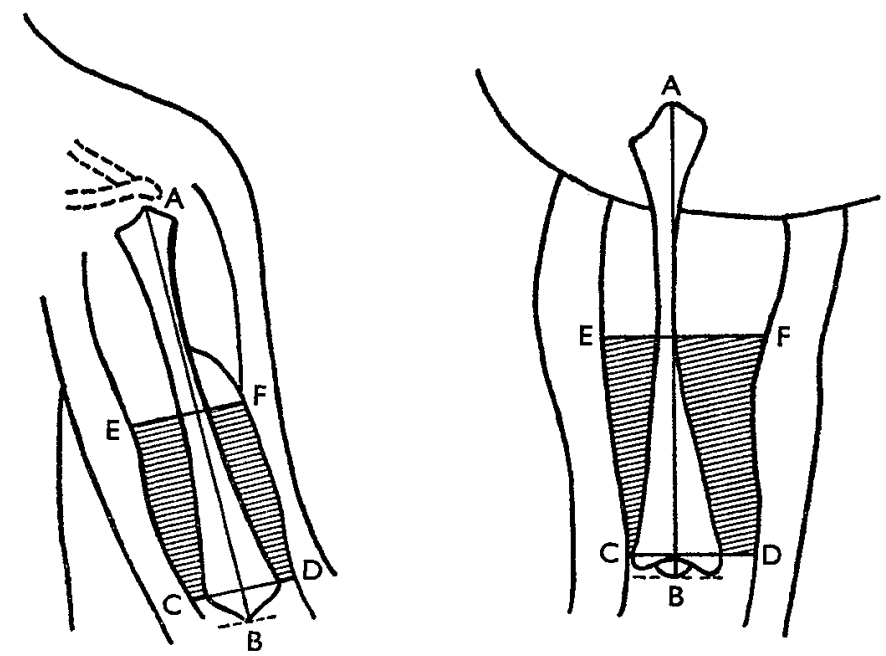

Fig. I. A diagram of the method used for measuring the X-ray muscle shadow weights of the upper arm and thigh of the children. For details see this page.

horizontal lines CD, EF. This is the shaded area in Fig. I. The weight of these segments of film was found and standardized for any variations in the X-ray film by punching out two small discs of film from each of the four edges and weighing the discs together. The weight density of each X-ray film was corrected to that of the first film used on the first patient. This method of quantification was easy to standardize and gave good replicate values.

\section{RESULTS}

The children lost their oedema after $\mathrm{I}-2$ weeks of treatment and their body-weights then increased, rapidly at first and then gradually more slowly, particularly after discharge. During recovery most of the children suffered periodic relapses, mainly due to infections, which temporarily stopped their growth or caused a loss of body-weight. However, on average, the children achieved considerable 'catch-up' growth over the period as a whole and Table $\mathrm{I}$ shows the mean percentage of expected weight for age at different stages of recovery. These values were calculated on the basis of the Harvard standards for males and females (Stuart \& Stevenson, I954). 
Vol. 25

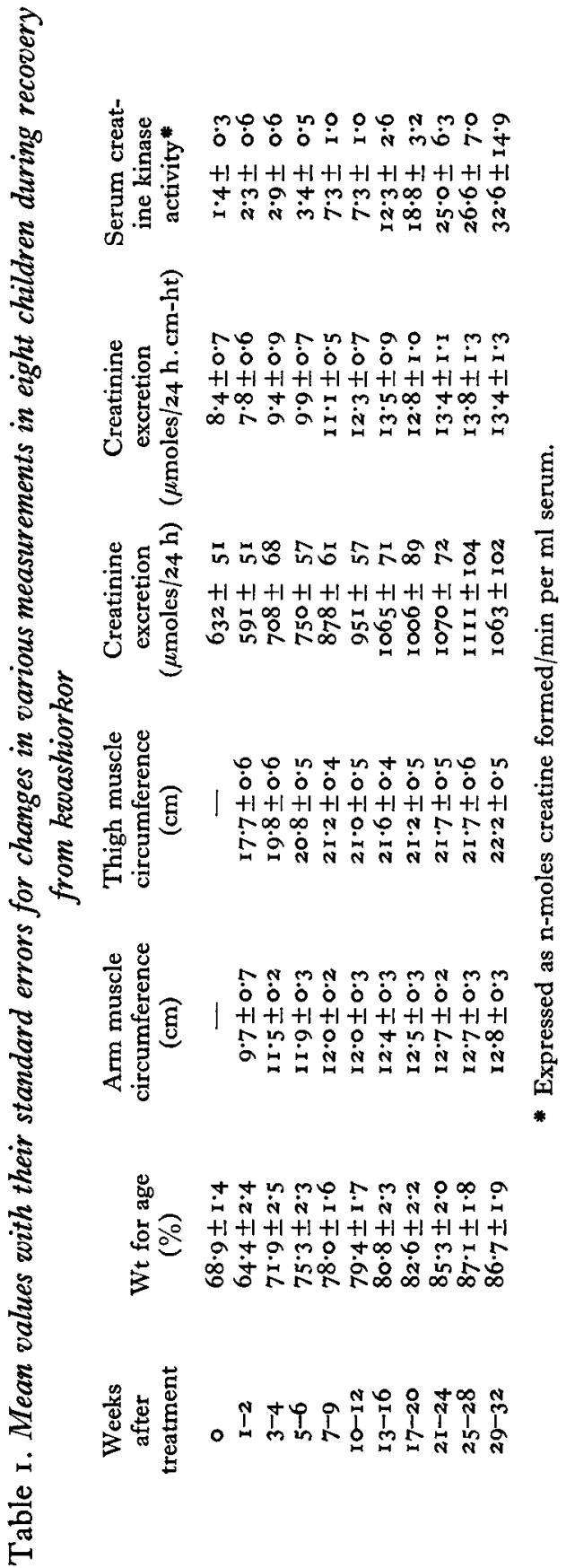


Table I also gives the mean values for changes in creatine kinase activity during rehabilitation. The levels were all low on admission, but they rose dramatically on treatment to values some twentyfold higher. This is in agreement with the results of Balmer \& Rutishauser ( 1968 ). The scatter of results was very small at the beginning but, because the increase in serum creatine kinase was more rapid and more fluctuating in some children than in others, the standard error at the end of the study was rather great.

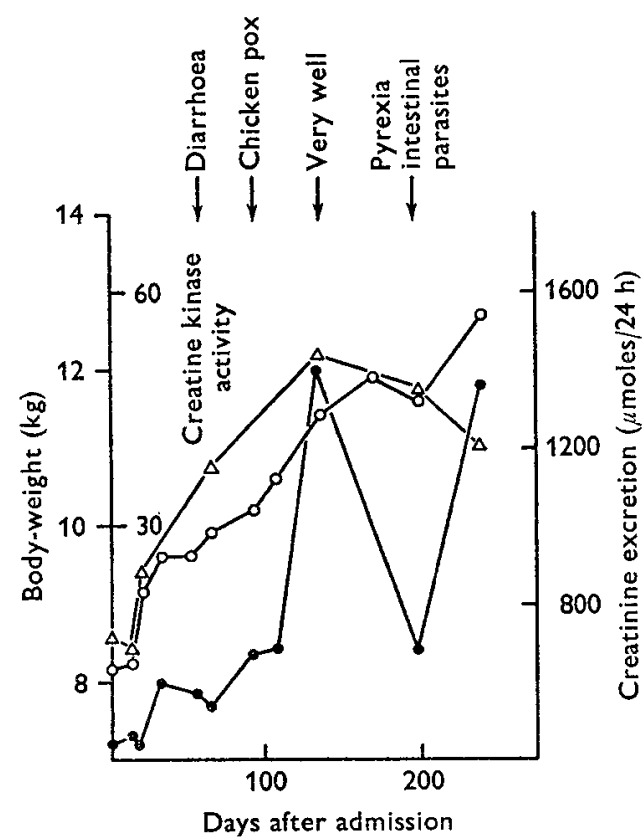

Fig. 2

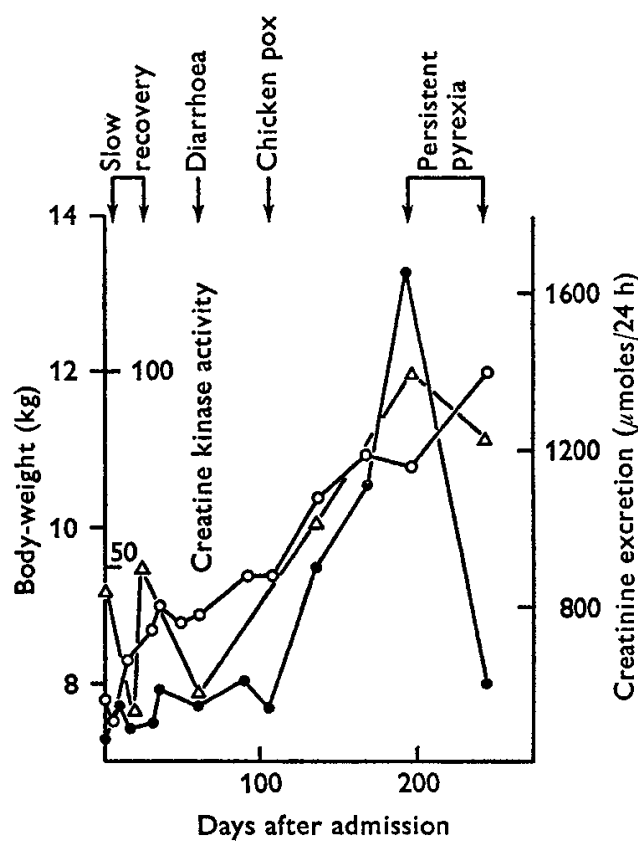

Fig. 3

Fig. 2. Changes in serum creatine kinase activity, urinary creatinine excretion and bodyweight in a Ugandan child recovering from kwashiorkor. - creatine kinase activity (expressed as $\mathrm{n}$-moles creatine formed/min per $\mathrm{ml}$ serum); $\mathrm{O}-\mathrm{O}$, body-weight; $\triangle-\triangle$, urinary creatinine.

Fig. 3. Changes in serum creatine kinase activity, urinary creatinine excretion and body-weight in a Ugandan child recovering from kwashiorkor. -O, creatine kinase activity (expressed as $\mathrm{n}$-moles creatine formed/min per $\mathrm{ml}$ serum); $\bigcirc-0$, body-weight; $\Delta-\Delta$, urinary creatinine.

The reason for this scatter was made clearer by examining the results for individual children. Typical examples are given in Figs. 2-4. Creatine kinase activity rose to high values when improvement in the general well-being of the children was greatest, but it dropped dramatically during episodes of ill health.

The other biochemical measurement recorded in Table $\mathrm{I}$ is creatinine excretion. Although the children were all about the same age, their heights on admission did range between 69 and $8 \mathrm{I} \mathrm{cm}$ and, therefore, the creatinine excretion has been expressed both as $\mu$ moles $/ 24 \mathrm{~h}$ per $\mathrm{cm}$-height and $\mu$ moles $/ 24 \mathrm{~h}$. Each measurement rose on rehabilitation and the percentage increase was about the same, but it was much less than the increase in serum creatine kinase activity. The scatter of values for creatinine 
excretion was also relatively small compared with that for creatine kinase. Examination of creatinine excretion in the individual children shown in Figs, 2, 3 and 4 shows that, although it was apparently affected by episodes of infection or infestation, often at the same time as creatine kinase, the values fluctuated much less markedly than the activities of the serum enzyme.

The committee for the appraisal of protein-calorie malnutrition of the International Union of Nutritional Sciences has been considering ways of standardizing the

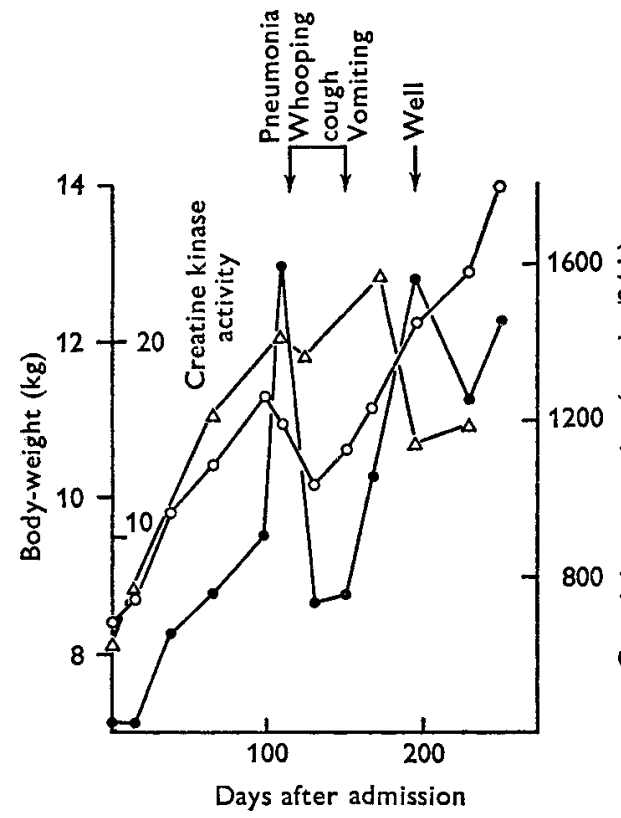

Fig. 4

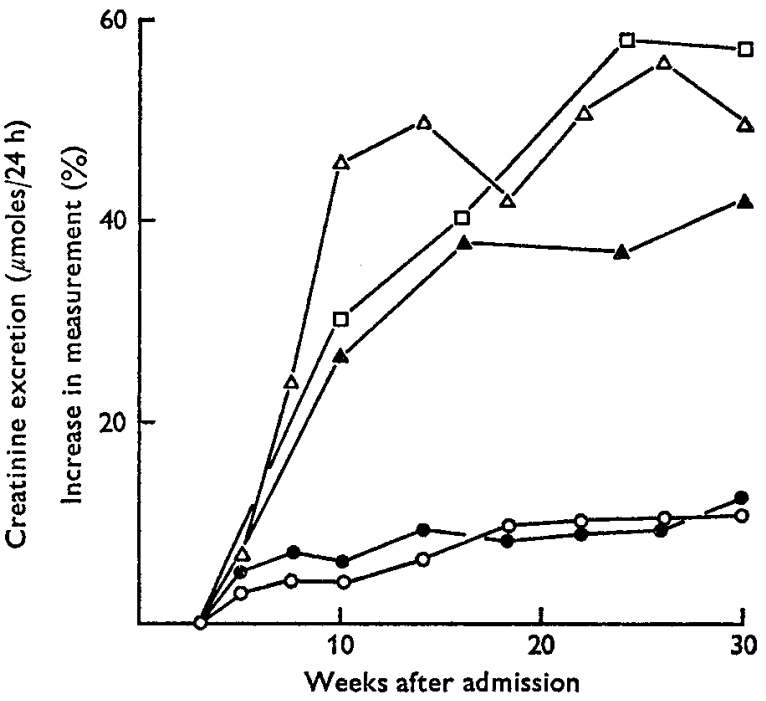

Fig. 5

Fig. 4. Changes in serum creatine kinase activity, urinary creatinine excretion and bodyweight in a Ugandan child recovering from kwashiorkor. - - creatine kinase activity (expressed as $\mathrm{n}$-moles creatine formed/min per $\mathrm{ml}$ serum); $\mathrm{O}-\mathrm{O}$, body-weight; $\triangle-\triangle$, urinary creatinine.

Fig. 5. Percentage increase, in children recovering from kwashiorkor, in the various measurements associated with musculature after the time of the first $\mathrm{X}$-ray. $\mathrm{O}-\mathrm{O}$, muscle circumference $(\mathrm{arm})$; -0 , muscle circumference (thigh); $\triangle-\triangle$, creatinine excretion; $\Delta-\Delta$, $\mathrm{X}$-ray weight (arm); $\square-\square$, X-ray weight (thigh).

procedures for the assessment of nutritional status. In this connexion Dr G. Arroyave (private communication) has recently analysed published values and produced a set of urinary creatinine standards for children according to height and age. The mean height of the children at the end of this study was $79.3 \mathrm{~cm}$ and the suggested normal creatinine excretion for children of this height is $15^{\circ} 4 \mu$ moles $/ 24 \mathrm{~h}$ per $\mathrm{cm}$-height. This is higher than the $13.4 \mu$ moles found, which indicates that the children might still have been depleted of muscle for their height even at the end of the study. Arroyave \& Wilson (196r) maintained that creatinine excretion did not return to normal in children recovering from kwashiorkor, even after receiving good diets, for periods up to 18 months. 
Table I also gives a summary of the anthropometric measurements which are supposed to reflect changes in muscle mass, the arm muscle circumference and the thigh muscle circumference. As with the biochemical measurements, these rose with treatment too and by the end of the study the arm muscle circumferences were only slightly below the values quoted for normal children of the same age (Jelliffe, I966). This is in contrast to creatinine excretion which on an age basis was well below the standard proposed by Dr Arroyave.

The radiographic measurements are given in Table 2. The values for both the arm and the thigh increased on rehabilitation, but again the change was most marked during the early stages of recovery. As might be expected from this type of measurement, there was no evidence of fluctuating values.

Table 2. Mean values with their standard errors for $X$-ray muscle shadow weights ( $m g$ ) of the arm and thigh in eight children recovering from kwashiorkor at different periods after admission to hospital (for details see p. 275)

$\begin{array}{lccccc} & \text { Weeks } & \text { Weeks } & \text { Weeks } & \text { Weeks } & \text { Weeks } \\ \text { Measurement } & 3-5 & 9-12 & \text { I4-I8 } & 20-26 & 27-31 \\ \text { Arm } & & & & \\ \text { Thigh } & \text { I9I } \pm 15 & 243 \pm 19 & 266 \pm 16 & 263 \pm 13 & 273 \pm 21 \\ & 539 \pm 18 & 703 \pm 36 & 758 \pm 19 & 853 \pm 45 & 853 \pm 16\end{array}$

A general impression of the similarities and inconsistencies amongst the different ways of assessing changes in musculature is given in Fig. 5, which shows the average percentage increase in the various measurements after the time of the first X-ray. Creatine kinase is not included because the percentage increase was so large, greater than 1000 . At the other extreme the anthropometric, muscle circumference, measurements rose by little more than 1o $\%$. The values showing the best agreement were the arm and thigh $\mathrm{X}$-ray weights and creatinine excretion, particularly the latter two.

The relationships between the different measurements were also tested by linear regression analysis. Urinary creatinine excretion was significantly correlated with arm and thigh muscle circumference, thus agreeing with Standard et al. (1959) and with the $\mathrm{X}$-ray muscle shadow weights. Creatine kinase showed similar significant correlations. However, these mathematical relationships were almost inevitable since all the measurements rose on recovery. The statistical findings did not add to the understanding of the biological factors involved in these relationships and therefore they have not been recorded in detail.

\section{DISCUSSION}

The main drawback in this investigation has been the lack of an absolute measure of muscle mass against which the more primitive tests could be judged. This measurement is difficult and the only hope would have been a whole-body counter which could have been used for assaying the potassium content of the child (D. Picou, personal communication). This is related to the lean body mass, of which the muscles form an important component. It has only been possible to compare and contrast the measurements against each other, but even so some useful conclusions can be drawn which indicate the techniques having the greatest potential. 
While there was some evidence that a rise in serum creatine kinase activity mirrored improvement in musculature, the fluctuations in activity, particularly in response to infection, were quite out of proportion to any possible changes in muscle tissue mass. Why the enzyme was so sensitive to intercurrent illness is not easy to explain but it should be remembered that the serum activity of any enzyme is the product of many different mechanisms, including the following: $(a)$ changes in the concentration of active enzyme protein in the cell, $(b)$ alterations in the distribution of the enzyme within the various cellular compartments, $(c)$ changes in the permeability of the cell membrane, (d) differences in the rate of elimination of the enzyme from the blood or in the rate of its deactivation, $(e)$ alterations in plasma volume or changes in the ratio between the amount of tissue releasing the enzyme and plasma volume. In view of these complexities, one is forced to wonder if the measurement of the serum activity of any enzyme will ever be of much value in assessing nutritional status. Some very specific abnormality would be necessary and of magnitude sufficient not to be swamped by changes in these other variables. Clearly this was not so with serum creatine kinase in the present study.

A possible explanation for the very low serum creatine kinase activities found in kwashiorkor, and during episodes of infection, could have been a reduction in the level of the tissue enzyme. An attempt was made to investigate this possibility in experimentally malnourished rats (Reindorp, I970) but no significant difference was found between control and malnourished muscles. Muscle cells are prone to changes in cell permeability (Griffiths, I 966) and this was another conceivable cause of the fluctuations, although no attempt was made to investigate this possibility. Transient changes in plasma volume are known to occur in Ugandan children with malnutrition (Leonard, MacWilliam \& Jones, I965) but not to the extent which could have accounted for all the spurious enzyme activities. Whatever the cause, the wild fluctuations in creatine kinase activity are a major limitation to its practical application.

Theoretically, creatinine excretion could have been affected by most of the factors outlined for creatine kinase plus additional complications associated with kidney clearance (Picou, Alleyne \& Seakins, 1965). Although there were unexpected fluctuations in creatinine excretion, the changes were by no means as marked as with the enzyme. Some of these may have related to a decreased synthesis of creatinine, as suggested by Srikantia, Pargaonkar \& Reddy (1965), although creatinine excretion is by no means constant even in normal adults (Cramér, Cramér \& Selander, r967).

During the course of recovery the biochemical, anthropometric and X-ray assessments gave different impressions about the percentage improvement in musculature. The reason for these differences is probably one of simple mathematics: the various techniques measured different criteria. Muscle circumference has only one dimension, and part of the measurement, the bone circumference, was essentially constant during the period under investigation. The X-ray weight, on the other hand, estimates more complex, two-dimensional changes in area, and creatinine excretion is related to total body musculature and is in fact a three-dimensional measurement. A small increase in each dimension produces a very much greater percentage change in a threedimensional than in the one-dimensional measurement. 
It is probably for this reason that the anthropometric measurements of arm and thigh muscle circumference were relatively insensitive to quite large changes in the musculature in those limbs. This, coupled with the difficulty of making accurate measurements in a squirming child, constitutes a limitation to this method. Anthropometric measurements of arm circumference are in common use as a public health index of protein-calorie malnutrition (Jelliffe \& Jelliffe, 1969). It is important, however, that the lack of sensitivity of this one-dimensional measurement is clearly understood, especially when even simpler measurements such as the 'quac stick' (Arnhold, I969) are contemplated.

It would seem that the measurement of urinary creatinine is a more sensitive way of estimating changes in musculature, although fluctuations due to extramuscular factors could give rise to spurious results in the individual. It has, unfortunately, the further disadvantage that a timed urine specimen, preferably $24 \mathrm{~h}$, needs to be collected.

If a $24 \mathrm{~h}$ urine collection proves to be impossible in practice, and it might be in a rural survey in a developing country, the measurement of X-ray muscle shadow weight offers potential and merits more detailed investigation. Before it can be used in surveys, the best way of quantifying the muscle shadow needs to be established and a set of standards based on this measurement to be prepared. A mobile X-ray system would also be necessary.

It is probable, however, that both the biochemical and radiographic methods will have many inherent difficulties, and in the absence of an absolute method of assaying depletion in musculature it might be wise to make both measurements. This would provide a more detailed 'muscle profile' which, theoretically, should be less misleading than a single measurement. lt is difficult, though, to see any role for creatine kinase in this context.

We thank Dr Michael Parkin, Dr Elizabeth Poskitt and Sister Frances Shaw and her nursing staff for supervising this investigation in the ward and Miss Ingrid Rutishauser for instruction in anthropometry. All the X-rays were taken by Dr G. Jones of Mulago Hospital, Kampala and we are grateful to him for detailed discussions on the results.

\section{REFERENCES}

Arnhold, R. (1969). F. trop. Ped. 15, 243.

Arroyave, G. \& Wilson, D. (1961). Am. F. clin. Nutr. 9, 170.

Arroyave, G., Sandstead, H. \& Schumacher, R. (1958). Fedn Proc. Fedn Am. Socs exp. Biol. 17, 469. Balmer, S. E. \& Rutishauser, I. H. E. (1968). F. Pediat. 73, 783 .

Cramér, K., Cramér, H. \& Selander, S. (1967). Clinica chim. Acta r5, 33 I.

Garn, S. M. (1962). Am. F. clin. Nutr. I1, 4r8.

Griffiths, P. D. (1966). Clinica chim. Acta 13, 4 I3.

Hughes, B. P. (1962). Clinica chim. Acta 7, 597.

Jelliffe, D. B. (1966). Monograph Ser. W.H.O. no. 53.

Jelliffe, E. F. \& Jelliffe, D. B. (I969). F. trop. Ped. I5, I77.

Leonard, P. J., MacWilliam, K. M. \& Jones, K. W. (1965). Trans. R. Soc. trop. Med. Hyg. 59, 582.

McFie, J. \& Welbourn, H. F. (1962). $\mathcal{F}$. Nutr. 76, 97.

Mendes, C. B. \& Waterlow, J. C. (I958), Br. F. Nutr. 12, 74.

Picou, D., Alleyne, G. A. O. \& Seakins, A. (1965). Clin. Sci. 29, 5 I7.

Reindorp, S. ( 1970 ). Changes related to muscle in protein calorie malnutrition. $\mathrm{PhD}$ Thesis, University of Cambridge. 
Srikantia, S. G., Pargaonkar, V. U. \& Reddy, V. (1965). Am. F. clin. Nutr. 16, 436.

Standard, K. I., Wills, V. G. \& Waterlow, J. C. (1959). Am. F. clin. Nutr. 7, 27 I.

Staff, T. H. E. (r968). E. Afr. med. F. 45, 399.

Stuart, H. C. \& Stevenson, S. S. (1954). In Textbook of Pediatrics 8th ed., p. 48 [W. E. Nelson, editor]. Philadelphia: Saunders.

Taussky, H. H. (1956). Clinica chim. Acta x, 2 10.

Viteri, F. E., Arroyave, G. \& Béhar, M. (1966). Proc. int. Congr. Nutr. vir. Hamburg p. 46.

Waterlow, J. C. (1956). W. Indian med. F. 5, 167.

Whitehead, R. G. (1968). In Calorie Deficiencies and Protein Deficiencies p. II5 [R. A. McCance and E. M. Widdowson, editors]. London: Churchill. 